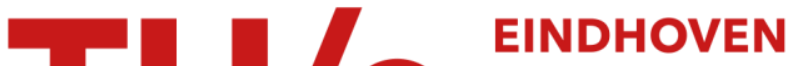 UNIVERSITY OF TECHNOLOGY
}

\section{High-performance liquid chromatography of mixtures of catechol and its reaction products with glyoxylic acid}

\section{Citation for published version (APA):}

Verhaar, L. A. T., Meuldijk, J., \& Wiele, van der, K. (1989). High-performance liquid chromatography of mixtures of catechol and its reaction products with glyoxylic acid. Journal of Chromatography, 472(2), 381-388.

https://doi.org/10.1016/S0021-9673\%2800\%2994137-2, https://doi.org/10.1016/S0021-9673(00)94137-2

DOI:

10.1016/S0021-9673\%2800\%2994137-2

$10.1016 / S 0021-9673(00) 94137-2$

Document status and date:

Published: 01/01/1989

\section{Document Version:}

Publisher's PDF, also known as Version of Record (includes final page, issue and volume numbers)

\section{Please check the document version of this publication:}

- A submitted manuscript is the version of the article upon submission and before peer-review. There can be important differences between the submitted version and the official published version of record. People interested in the research are advised to contact the author for the final version of the publication, or visit the $\mathrm{DOI}$ to the publisher's website.

- The final author version and the galley proof are versions of the publication after peer review.

- The final published version features the final layout of the paper including the volume, issue and page numbers.

Link to publication

\section{General rights}

Copyright and moral rights for the publications made accessible in the public portal are retained by the authors and/or other copyright owners and it is a condition of accessing publications that users recognise and abide by the legal requirements associated with these rights.

- Users may download and print one copy of any publication from the public portal for the purpose of private study or research.

- You may not further distribute the material or use it for any profit-making activity or commercial gain

- You may freely distribute the URL identifying the publication in the public portal.

If the publication is distributed under the terms of Article 25fa of the Dutch Copyright Act, indicated by the "Taverne" license above, please follow below link for the End User Agreement:

www.tue.nl/taverne

Take down policy

If you believe that this document breaches copyright please contact us at:

openaccess@tue.nl

providing details and we will investigate your claim. 

CATECHOL AND ITS REACTION PRODUCTS WITH GLYOXYLIC ACID

\section{A. Th. VERHAAR*, J. MEULDIJK and K. VAN DER WIELE}

Eindhoven University of Technology, Chemical Engineering Laboratory, P.O. Box 513, $5600 \mathrm{MB}$ Eindhoven (The Netherlands)

(Received December 22nd, 1988)

\section{SUMMARY}

Complex mixtures of catechol and its $\alpha$-hydroxyacetic acid derivatives formed by reaction with glyoxylic acid in aqueous alkaline media were analysed with highperformance liquid chromatography. A complete qualitative and quantitative analysis of the reaction was developed using a strong cation-exchange resin (SCX) and a reversed-phase $n$-octadecylsilane-modified silica (ODS) column combined with refractive index and fixed-wavelength UV detection. An almost identical elution pattern was observed for both columns, indicating a separation mechanism based on hydrophobic interactions. The ODS column appeared to be more selective than the SCX column towards the aromatic compounds.

\section{INTRODUCTION}

The reaction of catechol (1,2-dihydroxybenzene) with glyoxylic acid in aqueous alkaline media results in a complex mixture of $\alpha$-hydroxyacetic acid derivates. The reaction scheme is shown in Fig. 1.

The main and most interesting reaction product is $\alpha, 3,4$-trihydroxybenzeneacetic acid (the para derivative), from which 3,4-dihydroxybenzaldehyde can be obtained by selective catalytic oxidation. The para derivative may also be a precursor for other $\alpha$-substituted benzeneacetic acid derivatives (e.g., D,L-3,4-dihydroxyphenylglycine) or 3,4-dihydroxybenzeneacetic acid. All such products are interesting starting materials for specialities and pharmaceutical products.

The development of a process for the preparation of the para derivative on a technical scale requires a complete kinetic description of the electrophilic substitution reactions of glyoxylic acid with catechol and its monosubstituted $\alpha$-hydroxyacetic acid derivatives as shown in Fig. 1. A thorough investigation of the kinetics is possible only if an accurate method for the qualitative and a quantitative analysis of the reaction mixture is available.

Chromatographic techniques seem to be appropriate for the analysis of these complex reaction mixtures. Analysis for catechol is possible with gas-liquid chromatography $(\mathrm{GLC})^{1-3}$. Nothing appears to have been reported previously about the 


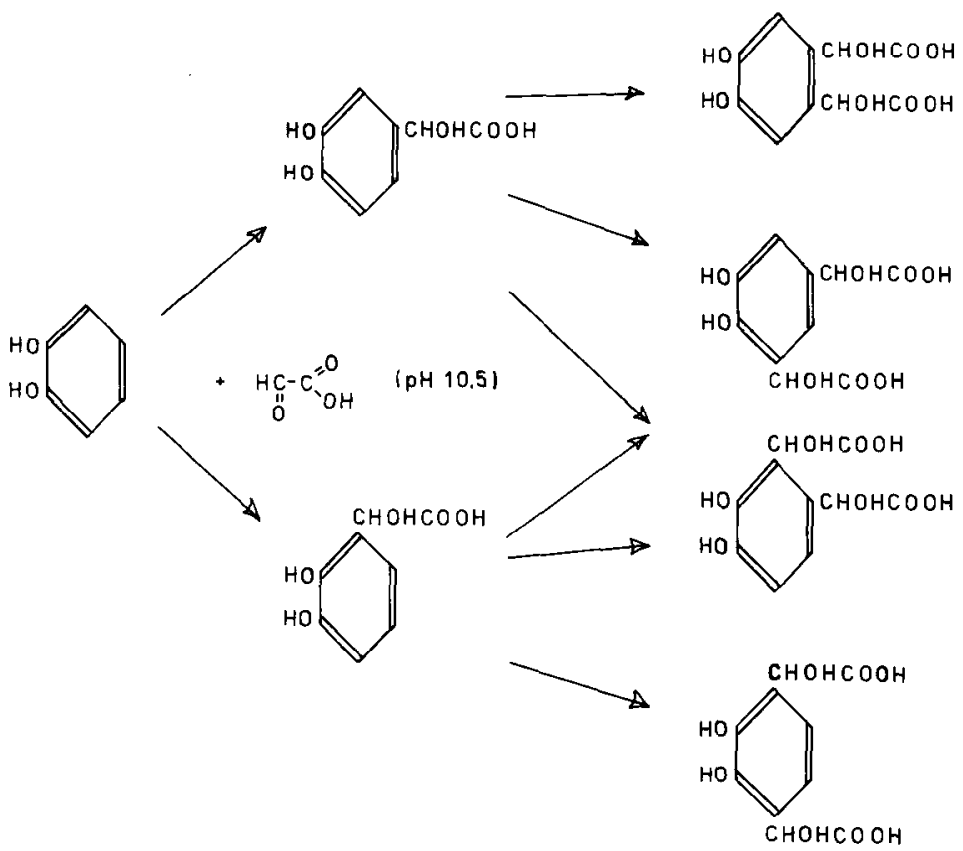

Fig. 1. Possible reactions in aqueous alkaline solutions of catechol and glyoxylic acid.

analysis of mixtures of catechol and its $\alpha$-hydroxyacetic acid derivatives. For the separation of the $\alpha$-hydroxyacetic acid derivatives of catechol by GLC, a time-consuming precolumn derivatization is necessary to increase their volatility and thermal stability. The application of liquid chromatography as separation technique for the components of the reaction mixtures of catechol and glyoxylic acid therefore seems an obvious choice. A procedure for the qualitative and quantitative analysis of reaction mixtures of glyoxylic acid and phenol or guaiacol (2-methoxyphenol) based on liquid chromatography has been described recently ${ }^{4}$. The chromatograms were obtained with a completely sulphonated copolymer of styrene and 1,4-divinylbenzene in the acidic form as the stationary phase and in an independent procedure with a reversed-phase system based on an $n$-octadecylsilane-modified silica phase ${ }^{4}$. For both columns the eluent was an aqueous $5 \cdot 10^{-3} \mathrm{~mol} / \mathrm{dm}^{3}$ sulphuric acid solution. It appeared useful to test the same method for the reaction mixtures of catechol and glyoxylic acid, which show a close resemblance to the less complicated reaction mixtures of glyoxylic acid and phenol or guaiacol. This paper describes the application of this slightly modified method to reaction mixtures of catechol and glyoxylic acid.

\section{EXPERIMENTAL}

\section{Materials}

Catechol and $\alpha, 3,4$-trihydroxybenzeneacetic acid were obtained from Janssen Chimica (Beerse, Belgium), phenol from Merck (Darmstadt, F.R.G.), glyoxylic acid (50 wt.- $\%$ in water) and sodium $\alpha, 4$-dihydroxybenzene acetate monohydrate from Andeno (Venlo, The Netherlands). 


\section{Apparatus}

The chromatographic system, stationary phases, column dimensions and eluent composition were the same as described previously for the analysis of reaction mixtures of glyoxylic acid and phenol or guaiacol ${ }^{4}$. The following abbreviations for the column-detection combinations are used: SCX-RI, a completely sulphonated copolymer of styrene and divinylbenzene $(8 \%)$ in the acidic form (a strong cationexchange SCX column) as stationary phase combined with refractive index detection; SCX-UV, the same stationary phase as above combined with UV detection at 254 $\mathrm{nm}$; ODS-RI, a stationary phase consisting of particles of $n$-octadecylsilane-modified silica (ODS column) combined with refractive index detection; and ODS-UV, the same ODS column as in the preceding system combined with UV detection.

\section{Sample preparation}

Samples for chromatography were taken from the solutions obtained during the reaction of catechol and glyoxylic acid. The reactions were carried out in aqueous solution at a constant $\mathrm{pH}$ of 10.50 and at constant temperatures between 25 and $50^{\circ} \mathrm{C}$. The reactions were started by mixing equimolar amounts of the reactants. Before mixing, the $\mathrm{pH}$ of the solution of catechol and glyoxylic acid was adjusted to 10.50 with concentrated sodium hydroxide solution. The concentration of the reactants immediately after mixing was generally $0.25 \mathrm{~mol} / \mathrm{dm}^{3}$. The reaction was quenched immediately after sampling by mixing the sample with an equal volume of $1 \mathrm{~mol} / \mathrm{dm}^{3}$ hydrochloric acid. The resulting solution $(\mathrm{pH}<1)$ was introduced into the chromatographic system without further treatment.

\section{RESULTS AND DISCUSSION}

The elution volumes of catechol, phenol and guaiacol as a function of the column temperature were determined for the SCX and ODS columns. From these elution volumes the capacity factors, $k^{\prime}$, were calculated as described by Simpson ${ }^{5}$. The results are given in Fig. 2, which shows an identical influence of the column temperature on the capacity factors for the three aromatic compounds on both columns, suggesting an identical retention mechanism. Retention originates from hydrophobic interactions between the non-polar parts of the stationary phase and the aromatic ring of the eluted compounds ${ }^{4}$. The hydrophobic character increases in the order catechol $<$ phenol $<$ guaiacol.

The samples taken from the reaction mixtures of catechol and glyoxylic acid were analysed with the SCX and ODS columns at $30^{\circ} \mathrm{C}$. Compared with the SCX column temperature of $85^{\circ} \mathrm{C}$ used in the analysis of reaction mixtures of glyoxylic acid and phenol or guaiacol ${ }^{4}$, the temperature of the SCX column in this study is low. The choice of this low column temperature can be explained by a slightly but continuously decreasing stability of catechol on increasing the temperature of the SCX column above about $30^{\circ} \mathrm{C}$. For the ODS column, no significant change in the molar response of catechol was observed for column temperatures between 20 and $60^{\circ} \mathrm{C}$. Higher column temperatures were not investigated because of the limited thermal stability of the stationary phase.

Typical examples of chromalograms of samples taken from reaction mixtures of catechol and glyoxylic acid obtained with the SCX-RI and ODS-RI column-detec- 


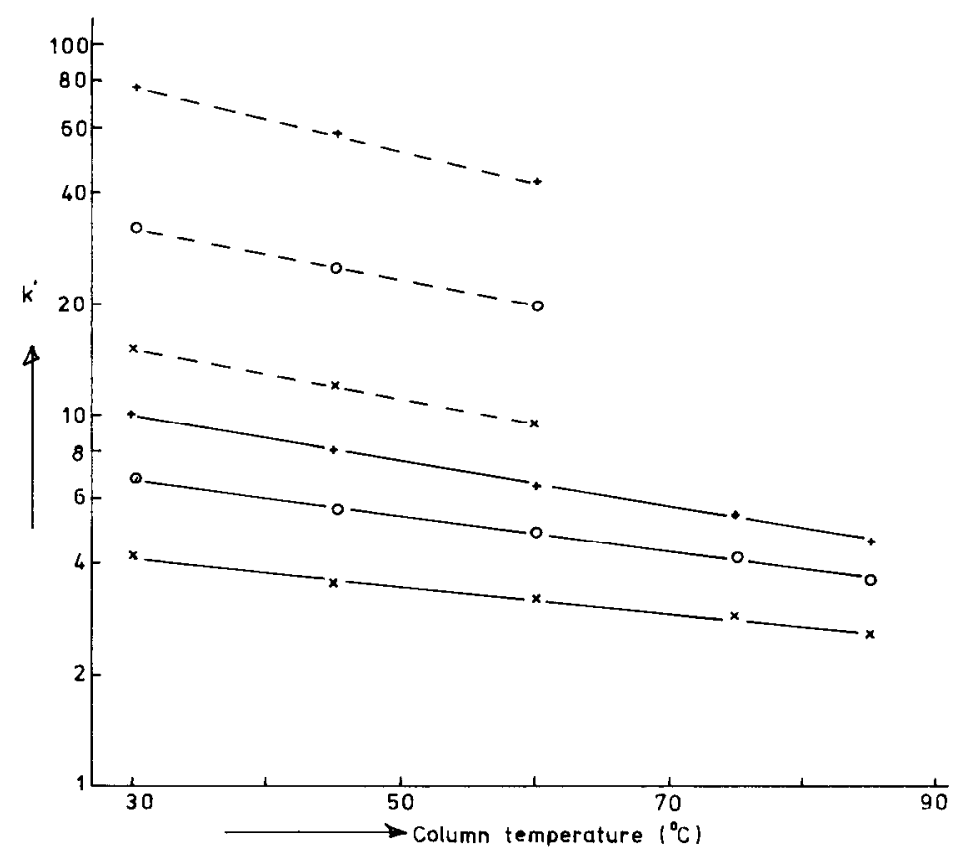

Fig. 2. Capacity factors $\left(k^{\prime}\right)$ of $(\bigcirc)$ phenol, $(+)$ guaiacol and $(x)$ catechol as a function of column temperature for (solid lines) the SCX and (broken lines) the ODS column.

tion combinations are shown in the Figs. 3 and 4, respectively. The results show that quantification of catechol is possible with both combinations. The position of the elution zone of $\alpha, 3,4$-trihydroxybenzene acetic acid (the para derivative) in the chromatograms of the reaction samples was assigned by comparing the chromatograms with those obtained after injection of a solution of the pure compound. The elution volume of $\alpha, 2,3$-trihydroxybenzene acetic acid (the ortho derivative) on the ODS column is assumed to be significantly higher than that of the para derivative as a result of a more pronounced hydrophobic interaction of the ortho derivative with the non-polar stationary phase. For the SCX column co-elution of the ortho and para derivatives is observed. The difference in selectivity with respect to the ortho and para derivatives can be explained in terms of the hydrophobic properties of the stationary phases in the SCX and ODS columns ${ }^{4}$. As a result of their more polar character, the elution volumes of the doubly substituted derivatives of catechol are expected to be lower than those of the ortho and para derivatives for both columns. In the chromatograms of the reaction samples obtained with the ODS-RI system (Fig. 4), only two elution zones are observed between the injection peak and the peak of the para derivative. With the ODS-UV combination it was demonstrated that these elution zones can be assigned to aromatic compounds and therefore to doubly substituted derivatives of catechol.

Considering the structures of the four possible doubly substituted isomers, a different elution behaviour for each of these compounds may be expected on the ODS column. Probably only two isomers are formed in detectable amounts: $\alpha, \alpha^{\prime}, 4,5$-tetrahydroxybenzene-1,3-diacetic acid (the ortho,para derivative), from the ortho and the 

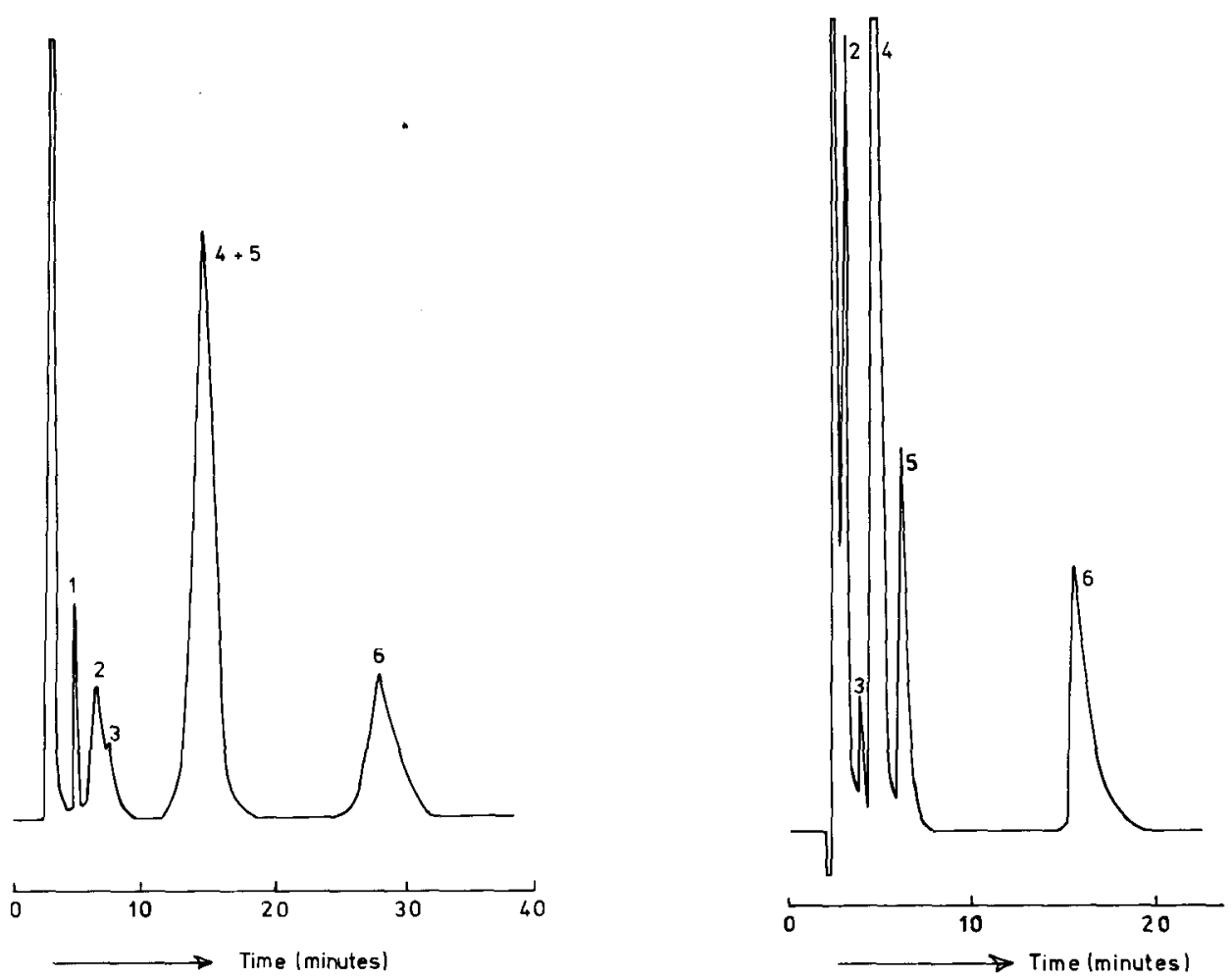

Fig. 3. Chromatogram of a sample from a reaction mixture of catechol and glyoxylic acid obtained with the SCX-RI combination. Analytical conditions as given under Experimental and in ref. 4. Column temperature $30^{\circ} \mathrm{C}$; flow-rate of the eluent, $0.4 \mathrm{ml} / \mathrm{min}$. Peaks: $1=$ glyoxylic acid; $2=\alpha, \alpha^{\prime}, 4,5$-tetrahydroxybenzene-1.3-diacetic acid; $3=\alpha, \alpha^{\prime}, 2,3$-tetrahydroxybenzene-1,4-diacetic acid; $4=\alpha, 3,4$-trihydroxybenzeneacetic acid; $5=\alpha, 2,3$-trihydroxybenzeneacetic acid; $6=$ catechol.

Fig. 4. Chromatogram of the same sample as in Fig. 3 obtained with the ODS-RI combination. Conditions as in Fig. 3, except flow-rate of the eluent, $0.8 \mathrm{ml} / \mathrm{min}$. Peaks as in Fig. 3.

para derivatives, and $\alpha, \alpha^{\prime}, 2,3$-tetrahydroxybenzene-1,4-diacetic acid (the ortho, ortho derivative), from the ortho derivative. The formation of $\alpha, \alpha^{\prime}, 3,4$-tetrahydroxybenzene-1,2-diacetic acid from the ortho derivative and the formation of $\alpha, \alpha^{\prime}, 4,5$-tetrahydroxybenzene-1,2-diacetic acid from the para derivative are probably prevented by the steric hindrance caused by the $\alpha$-hydroxyacetic acid group, already present in the singularly substituted derivative. As the hydrophobic properties of the ortho,ortho derivative are more pronounced than those of the ortho,para derivative, the elution volume of the ortho,para derivative on the ODS column will be significantly lower than that of the ortho,ortho derivative. For the SCX column, the elution peak of the ortho,ortho derivative appears as a shoulder to the rear part of the elution peak of the ortho,para derivative. This interpretation is supported by a chromatogram obtained with the SCX-UV combination. In this chromatogram, the same elution zones are observed as for the SCX-RI systern, with the exception of the peak immediately following the injection peak in the SCX-RI system. This peak should therefore be 
assigned to the elution of glyoxylic acid. Summarizing, it can be concluded that the elution volumes on the SCX column increase in the order glyoxylic acid < ortho,para $<$ ortho,ortho $<$ para $\approx$ ortho derivative $<$ catechol. For the ODS column, on which only retention of the aromatic compounds can be expected, an almost identical sequence of the elution volumes is observed, viz., ortho,para $<$ ortho,ortho $<$ para $<$ ortho derivative $<$ catechol.

The SCX-RI and ODS-RI combinations are both necessary for complete quantification of the reaction mixture. The ODS-RI combination has to be used for the quantification of the aromatic components in the reaction mixture, whereas the determination of the concentrations of catechol and glyoxylic acid is possible with the SCX-RI system.

The molar response of the ortho derivative and both doubly substituted derivatives of catechol, which are not available as pure compounds, can be calculated from the molar responses of catechol and the para derivative. For this calculation procedure, it is assumed that for a given number of $\alpha$-hydroxyacetic acid groups present, the molar response for refractive index detection is independent of the position of the substituents in the aromatic ring. It is further assumed that for RI detection a linear relationship exists between the molar response and the number of $\alpha$-hydroxyacetic acid groups present. These assumptions are supported by the values of the difference between the molar responses of $\alpha, 3,4$-trihydroxybenzeneacetic acid and catechol and the difference between the molar responses of $\alpha, 4$-dihydroxybenzeneacetic acid and phenol. The ratios of the measured values of the molar responses of these four compounds and the molar response of phenol are presented in Table I. These relative molar responses show that the difference between the molar responses of $\alpha, 3,4$-trihydroxybenzeneacetic acid and catechol is identical with that between the molar responses of $\alpha, 4$-dihydroxybenzeneacetic acid and phenol, within experimental error. This equality can lead to the conclusion that the change in the molar response after introduction of an $\alpha$-hydroxyacetic acid group is independent of the other substituents in the ring.

These considerations support our assignment of the elution peaks in the chromatograms obtained with the SCX-RI (Fig. 3) and ODS-RI combinations (Fig. 4) to the doubly substituted derivatives $\alpha, \alpha^{\prime}, 4,5$-tetrahydroxybenzene-1,3-diacetic acid and $\alpha, \alpha^{\prime}, 2,3$-tetrahydroxybenzene-1,4-diacetic acid given above. From Fig. 4 (ODS-RI) and the assumed equality of the molar responses of both doubly substituted derivatives, it can be concluded that the concentration of the ortho,para derivative responsible for the first elution peak is much greater than that of the ortho,ortho derivative

TABLE I

RELATIVE MOLAR RESPONSES OF PHENOL, CATECHOL AND THEIR PARA-SUBSTITUTED $\alpha$-HYDROXYACETIC ACID DERIVATIVES

\begin{tabular}{|c|c|}
\hline Compound & $\begin{array}{l}\text { Relative molar } \\
\text { response }\end{array}$ \\
\hline Phenol & 1.00 \\
\hline$\alpha, 4$-Dihydroxybenzeneacetic acid & 1.57 \\
\hline Catechol & 1.16 \\
\hline$\alpha, 3,4$-Trihydroxybenzeneacetic acid & 1.72 \\
\hline
\end{tabular}


TABLE II

RELATIVE MOLAR RESPONSES OF CATECHOL, GLYOXYLIC ACID AND THEIR REACTION PRODUCTS FORMED IN AQUEOUS ALKALINE SOLUTIONS

\begin{tabular}{ll}
\hline Compound & $\begin{array}{l}\text { Relative molar } \\
\text { response }\end{array}$ \\
\hline Catechol & 1.00 \\
Glyoxylic acid & 0.42 \\
$\alpha, 3,4-$ Trihydroxybenzeneacetic acid & 1.48 \\
$\alpha, 2,3-$ Trihydroxybenzeneacetic acid & 1.48 \\
$\alpha, \alpha^{\prime}, 4,5$-Tetrahydroxybenzene-1,3-di- & 1.96 \\
acetic acid & \\
$\alpha, \alpha^{\prime}, 2,3$-Tetrahydroxybenzene-1,4-di- & 1.96 \\
acetic acid &
\end{tabular}

assigned to the second elution zone on the ODS column. This difference in the amounts of the ortho,para and ortho,ortho derivatives is confirmed by the reaction scheme in Fig. 1 and by the ratio of the concentrations of the monosubstituted para and ortho derivatives, which is much higher than unity during the whole course of the reaction.

Table II shows the ratios of the molar responses of the components in the reaction mixtures of catechol and glyoxylic acid and the molar response of catechol for RI detection. With these values and the molar response of catechol, the concentra-

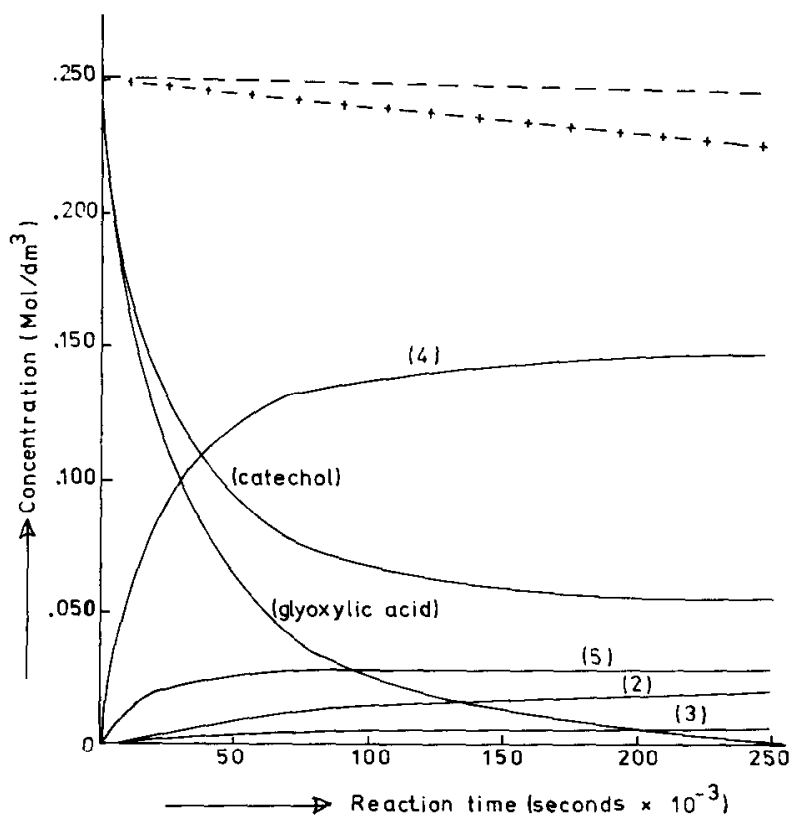

Fig. 5. Aromatic (- - - ) and glyoxylic acid equivalents $(-+-+-)$, and the concentrations of the components of a reaction mixture of catechol and glyoxylic acid as a function of time. Solvent, water; temperature, $25^{\circ} \mathrm{C} ; \mathrm{pH}, 10.50$. The numbers of the components correspond to those in Fig. 3 . 
tions of the various compounds in the reaction mixture can be calculated from the responses of the RI detector. Fig. 5 shows the concentrations of the various components in the reaction mixture as a function of time for a reaction at $25^{\circ} \mathrm{C}$ and a $\mathrm{pH}$ of 10.50 , and indicates a complete mass balance for the aromatic compounds in the reaction mixture for a glyoxylic acid conversion between 0 and 1 . The glyoxylic acid concentrations and the concentrations of the $\alpha$-hydroxyacetic acid derivatives in the reaction mixture show that the mass balance for glyoxylic acid is not fully complete. For a complete conversion of glyoxylic acid, only about $90 \%$ of the glyoxylic acid is converted into $\alpha$-hydroxyacetic acid derivatives. A few percent may be converted into glycolic and oxalic acid by the Cannizzaro reaction during the preparation of the starting solution. The nature of the other side-products formed from glyoxylic acid could not simply be determined. In the chromatograms obtained with the SCX-RI combination, no elution of eventual side-products of glyoxylic acid was observed.

\section{CONCLUSIONS}

Mixtures of catechol and its reaction products with glyoxylic acid can be characterized qualitatively by using high-performance liquid chromatography. The separation mechanism is based on hydrophobic interactions for both ODS and SCX columns.

The concentrations of the aromatic compounds can be determined with the ODS-RI combination and glyoxylic acid and catechol can be quantified using the SCX-RI combination. In the same way as for reaction mixtures of glyoxylic acid and phenol or guaiacol, it has been shown that reaction mixtures of catechol and glyoxylic acid can be completely quantified, even if not all aromatic reaction products are available in the pure form.

It is likely that the molar response using RI detection can be calculated from the contribution of the starting aromatic compounds and that of the $\alpha$-hydroxyacetic groups attached to the ring. The contribution of each $\alpha$-hydroxyacetic acid group is independent of the kind and number of substituents already present.

\section{REFERENCES}

1 I. O. O. Korhonen and J. Knuutinen. Chromatographia, 17 (1983) 154.

2 J. S. O'Grodnick, G. D. Dupré, B. J. Gulizia, S. H. Blake and R. A. Kuna, J. Chromatogr. Sci., 21 (1983) 289.

3 H. Mayer, J. Nolte and B. Paschold, Fresenius' Z. Anal. Chem., 315 (1983) 708.

4 L. A. Th. Verhaar, J. Meuldijk, W. P. Th. Groenland and K. van der Wiele, J. Chromatogr., 437 (1988) 185.

5 C. F. Simpson, Practical High Performance Liquid Chromatography, Heyden, London, 1976, p. 7. 